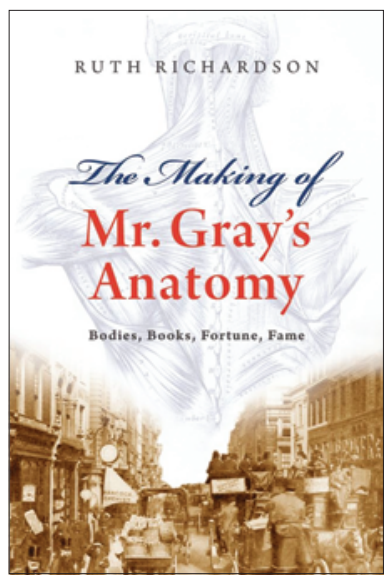

\title{
The making of Mr. Gray's anatomy
}

Bodies, books, fortune, fame

\author{
Ruth Richardson \\ Oxford University Press. New York, New York, USA. 2008. \\ 322 pp. \$29.95. ISBN: 978-0-19-955299-3 (hardcover).
}

\section{Reviewed by John T. Hansen}

Department of Neurobiology \& Anatomy and Office of Medical Education, University of Rochester Medical Center, Rochester, New York, USA.

E-mail: john_hansen@urmc.rochester.edu

be making of Mr. Gray's anatomy chronicles the fascinating story of one of the most widely known medical textbooks in the world as told through the work of two young men: Henry Gray, anatomist, surgeon, and author, and Henry Vandyke Carter, apothecary-surgeon, physician, and illustrator. Historian Ruth Richardson, of the Department of History at the University of Hertfordshire and the Department of History and Philosophy of Science at the University of Cambridge, weaves a wonderful tale of dissection, medicine, publishing, printing, illustration, marketing, and sales that culminates in the book often referred to as the "doctor's bible." Written to commemorate the 150th anniversary of Gray's anatomy, Richardson immerses the reader into the Dickensian back streets of midVictorian London to reveal the chance encounter of two very different men of medicine whose unlikely collaboration launched a masterpiece.

In 1842, Henry Gray, a young man of modest educational background, entered St. George's Hospital at the age of 15 to begin his medical studies as a surgeon and emerged 10 years later known for several important scholarly works and for his election into membership as a Fellow of the Royal Society at the age of 25. Henry Gray was a handsome man of medium height, a bit of a "dandy," and known as hardworking, focused, clever, status hungry, and professionally ambitious. Unfortunately, Gray still emerges as a mostly enigmatic person whose life we know about only through the scant writings of those who knew him, none of whom ever wrote a contemporary biography or personal memoir. Gray's Anatomy, descriptive and surgical was conceived, written, illustrated, and published in three years' time, appearing in 1858, when Gray was 31 . Three years later Gray, although vaccinated in childhood, died a swift and tragic death of confluent smallpox while attending his ill nephew.

Equally fascinating is the parallel story of the shy and reflective Henry Vandyke Carter, about which much is known through the diary he kept from the age of 14. Unable to afford the cost of an education that would formally prepare him to become a physician, Carter chose instead to train as an apothecary and then qualify as a surgeon; the apothecary-surgeons of that time were the equivalent of general practitioners in England. In 1848, at the age of 17 , serving as an apprentice to a London apothecary-surgeon, Carter entered medical school at St. George's Hospital, where he probably met Henry Gray for the first time. Their meeting most likely occurred in the dissection laboratory where Gray, age 21, was teaching anatomy and working on his first major work in embryology and comparative anatomy. It was in 1850, while both men were attending ward rounds and postmortems, that Henry Gray discovered that Carter was an accomplished artist, thus marking the beginning of a short but very fruitful, and sometimes contentious, collaboration that culminated in Gray's first book, The structure and use of the spleen, and in the publication of his opus, Gray's anatomy.

Gray's anatomy was a groundbreaking text known for its clear and concise descriptions complemented by Carter's beautiful woodcut images brilliantly rendered in light and shadow. The book provided medical students with an affordable, richly illustrated, and easily navigable textbook of anatomy that was the perfect companion for labo- ratory dissection and classroom study. Both men knew what students needed and wanted, and both brought their dissection skills, keen sense of the visual, and medical knowledge to the fore in creating this landmark volume.

Richardson does a masterful job of writing a book within a book. Her focus is on the creation and publication of Gray's anatomy, but she also skillfully weaves a tapestry of life, first as a medical student and academic, then as one who procures and dissects cadavers, and finally as one absorbed in the details of writing, illustrating, printing, publishing, and marketing a textbook of the size and complexity of Gray's anatomy. Richardson's book is thoroughly researched, meticulously referenced, appropriately annotated, richly illustrated, and vividly written in an absorbing style that is both scholarly and passionate. The only annoyance for some readers may be Richardson's digression into the process of publishing and marketing a book of this magnitude during the mid-nineteenth century. However, I feel this adds contextual historical richness to the story and provides insight into the immense nature of Gray's, Carter's, and their publisher's accomplishments over the three years that brought the book to fruition and guaranteed its relevance even to our present day British and American editions. Finally, Richardson is not afraid to critique her subjects' personalities or scholarly accomplishments and leaves no stone unturned in this compelling historical narrative. The reader doesn't have to be an anatomist, physician, or historian to appreciate this all-too-human story of a bygone era and the author and artist whose legacy survives to this very day. 